Session 3253

\title{
A Multidisciplinary Course Sequence Stressing Team Skills, Conceptual Design, Creative Problem Solving, Professional Practice, and Computing Skills for Students Entering The William States Lee College of Engineering
}

\author{
by \\ William Shelnutt, Mike Allen, Vivek Badami, Kim Buch, Art Edwards, Curtis Ensley, \\ Johnny Graham, David Schmidt, Silvia Middleton, Howard Phillips, and Patricia Tolley \\ of the University of North Carolina at Charlotte \\ and Monika Lumsdaine \\ of Michigan Technological University
}

\begin{abstract}
At UNC Charlotte, a faculty team is offering a new sequence of two courses, ENGR 1201 and 1202, Introduction to Engineering Practice and Principles I and II, for all students entering The William States Lee College of Engineering. Our long-range goals for this course sequence include (a) using the course as a foundation for lifelong learning of computer, teamwork, creative thinking, professional, and personal development skills and attitudes, (b) widespread faculty involvement in the course sequence over time, leading to incorporation of demanding team and creative thinking skills in disciplinary courses, (c ) an appreciation by students and faculty of the power of diversity in team and individual thinking style preferences, and (d) through feedback and continuous improvement, evolution of the course sequence to meet the changing needs of all stakeholders, while maintaining the integrity of the foundational purpose.

ENGR 1201 is an introductory two-semester hour course in which students are assigned to multidisciplinary teams to work on a semester-long conceptual design project while simultaneously receiving instruction and assignments in basic computing skills, personal development, team skills and tools, project planning, creative problem solving, introduction to disciplines, professional practice, and technical presentations. With few exceptions these topics are related to the semester design project, and exercises are designed to complement the project's progress. The course culminates in team presentations which are evaluated and scored by faculty from participating departments. Extensive evaluation of the course by students and faculty have led to improvements such as decreasing the number of assignments, coordinating assignments among participating faculty, and linking the assignments more closely to the semester project.

ENGR 1202 continues the emphasis on team skills and incorporates a discipline-specific laboratory component. Students choose laboratory sections corresponding to their majors and are assigned to teams which carry over to the common classroom sessions. In the disciplinary labs students are given instruction in the application of an introductory topic (such as engineering graphics or a computer language) and are assigned an open-ended semester-long conceptual design project utilizing the tools of that topic. The classroom portion of ENGR 1202 reinforces the team skills begun in ENGR 1201 and adds specific instruction and exercises in creative problem solving tools and techniques applicable to teams. Again, classroom instruction and
\end{abstract}


exercises parallel typical project progress, and the class culminates in team project presentations scored by participating faculty. In ENGR 1202, however, a comprehensive final exam tests students' understanding of both topical material from the laboratory sessions and material on tools of creative problem solving in teams. As in the preceding course, ENGR 1202 is also undergoing continuous improvement based on feedback from the students and faculty.

\section{Introduction}

The need for engineering graduates to be proficient at working in teams and in creative problem solving is increasingly voiced both by employers and by the Accreditation Board for Engineering and Technology ${ }^{\mathrm{i}}$, which is itself perhaps a reflection of the needs of industry ${ }^{\text {ii iii }}$. Of course, setting up and coaching teams in relatively small classes has been practiced here and elsewhere for some time. The questions we faced in 1994/95 were whether such a feat could be accomplished effectively for all students entering the college (about 500 per year for The William States Lee College of Engineering at the University of North Carolina at Charlotte), and whether such a course would receive the support from faculty and chairs in the various departments necessary to make the venture work. We, a multidisciplinary team of faculty from several departments, feel we have begun to address these needs and questions with a sequence of two new courses, initially offered in the fall of 1995 as a part of our new curricula ${ }^{1}$ designed for all new students entering the college. Our co-author, Monika Lumsdaine, has provided assistance in team formation and functioning using the HBDI (the Herrmann Brain Dominance Instrument). The courses, designated ENGR 1201 and ENGR 1202, Introduction to Engineering Practice and Principles I and II, are taught and managed by a team approach which appears to be working well.

\section{Long Range Goals of the Course Sequence}

The vision for this course sequence arises from the strategic plan for the college, reported elsewhere ${ }^{\text {ii }}$, which stresses the importance of lifelong learning by our students as they enter the workplace. Thus the long range goals for the 1201/1202 sequence include:

- Serving as a foundation for lifelong learning of computer, teamwork, creative thinking, professional, and personal development skill and attitudes;

- Affording students an early experience of the "fun" of engineering design and problem solving which probably attracted them to the field in the first place;

- Widespread faculty involvement in ENGR 1201/1202 over time, leading to incorporation of demanding team and creative thinking skills in disciplinary courses;

- evolution of the course sequence to meet the changing needs of all stakeholders, while maintaining the integrity of these founding purposes.

The goal of widespread faculty involvement has been both challenging and rewarding. It has led us to choose a rather unorthodox team approach to developing and teaching the course sequence.

\footnotetext{
${ }^{1}$ This course sequence is a part of a general curriculum restructuring of which the common freshman year was implemented in the fall of 1995. It is supported by the SUCCEED NSF coalition as a part of implementation of "Curriculum 21" which involves the integration of TQM into the content and delivery of engineering education.
} 


\section{The 1201/1202 Team}

Rather than have a single faculty member responsible for each of the two courses, we chose to use the team principles we are teaching students to manage and teach the course sequence itself. We proposed a team management scheme, as shown in Figure 1, to the college's academic council (Dean and Chairs), and with the council's sanction, we have used that approach, with some modifications, over the first two years of course offerings. The 1201/1202 faculty team is composed of lead instructors and guest lecturers from various departments in the college.

Typically, the team meets three times per semester and the team leader and the lead instructors set the agenda. The first meeting is held just prior to the beginning of the semester to review proposed course changes based on student feedback and lessons learned from the instructors. Students provide both quantitative and qualitative feedback in the form of a course evaluation given as the final exam in ENGR1201. In ENGR 1202, a conventional examination over course material substitutes for the course evaluation "final" of ENGR 1201, so most of the changes in ENGR1202 have been influenced by anecdotal feedback and a standard end-of semester course evaluation, as well as a desire to better integrate and build upon the material introduced in ENGR 1201. The lead instructors may propose changes as long as the original objectives of the courses are not compromised. However, all changes must be approved by the 1201/1202 team. The second meeting is typically held in mid-semester. Results of mid-semester student course evaluations, lessons learned to date, and/or other topics associated with either of the courses are discussed. Members of the team openly share their ideas and experiences with the expectation that the course will continue to evolve and improve, deriving benefits from the teamwork for students and faculty alike. Another meeting is usually scheduled just before the end of the semester to finalize preparations for team project presentations and course evaluations, to discuss preparations for the following semester, and to share any additional lessons learned.

\section{ENGR 1201 Learning Objectives}

We selected learning objectives for ENGR 1201 as the basic platform on which to build team and creative problem solving skills in succeeding courses in the sophomore, junior, and senior years. Our objectives are that, upon completion of ENGR 1201, students have the ability to:

- work productively together in teams;

- use computers and computational tools afforded by the college;

- begin a pattern of lifelong personal development and professional development;

- contrast and integrate the various engineering and computer science disciplines;

- make effective technical presentations;

- plan technical team projects;

- appreciate and take advantage of diversity in thinking preferences.

To accomplish these goals we designed ENGR 1201 around two parallel thrusts, a semesterlong conceptual design project and simultaneous instruction and assignments in selected topics (see Table 1). With few exceptions, these topics are tied to the semester design project, and exercises are timed to complement the project's progress. The course culminates in team 
presentations which are evaluated and scored by a cadre of faculty from the various departments in the college (as well as some faculty from Business and English).

The course topics in ENGR 1201 include the following clusters:

- computing skills (e-mail, world wide web, word processing, spreadsheets, presentation graphics, information access);

- $\quad$ personal development (Covey's 7 Habits $^{\text {iv }}$ and the HBDI);

- team skills and tools (communication, valuing diversity in thinking preferences, brainstorming, and team roles);project planning (Gantt charts);

- creative problem solving (conceptual design, Pugh Method, steps in problem solving);

- an introduction to disciplines (Civil, Electrical, Mechanical, and Computer Science);

- technical presentations (effective organization, visual aids, and establishing credibility);

- professional expectations and ethics (sage advice from the Dean on jobs, history of engineering, and professionalism).

The semester project was conceived from the first as the glue that holds it all together. We have strived to create an air of realism (and fun) with which freshmen could identify. During the first semester we had each team create a conceptual design of an elevator system for a high rise building, which resulted in some very innovative and creative designs. In that semester we

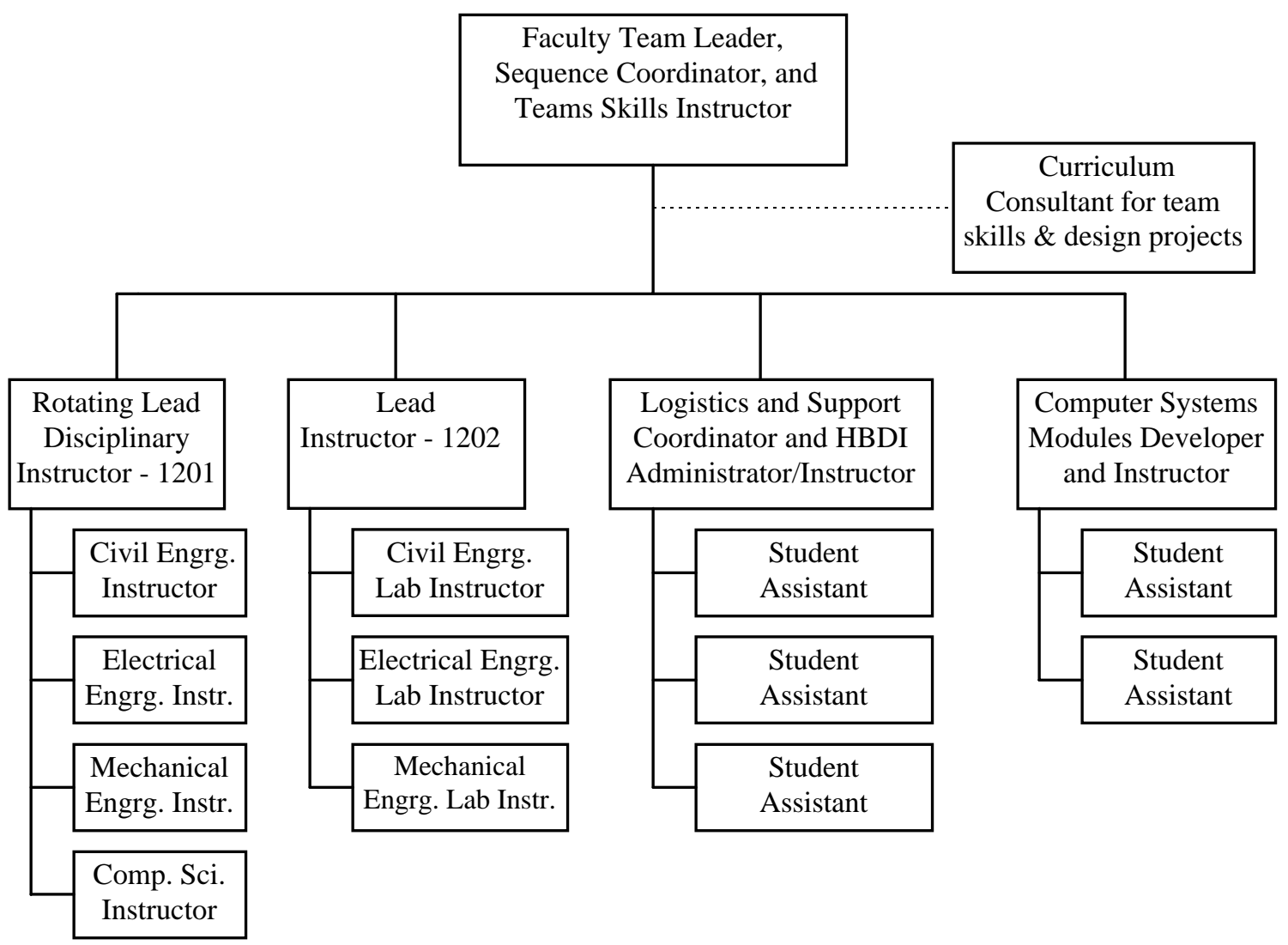

Figure 1. 1201/1202 Faculty Team Structure 
Table 1 - Topical Outline for ENGR 1201 Engineering Practice and Principles I as of Spring Semester, 1997. (2 sessions per week in a 15 Week Semester)

$\underline{\text { Session }}$ Topic

Course Plan, grading, expectations

Introduction to the College of Engineering Experience

Introduction to Covey's 7 Habits of Highly Effective People

MOSAIC computer system and the internet

Team Assignments and Project Topic

Careers and Professionalism

Snyder/McIntyre
Team Development and use of the HBDI

Use of the library for engineering research

Project Goals and objectives

Project Planning

HBDI Interpretation

Handling Conflict and Peer Evaluation

Conceptual design using Pugh method; invention disclosure History of engineering and computer science

Discussion of 7 Habits assignment; time management.

Curriculum purpose and structure

Project Update

Introduction to Civil Engineering

Jobs, salaries, and graduate study

Introduction to Mechanical Engineering

Project Update

Introduction to Electrical Engineering

Communication and presentation skills

Introduction to Computer Science

Project Update and Peer Evaluation

Engineering Technology/ International Option

Student presentations

Student presentations

Feedback on project and presentations from faculty evaluators

Final Exam (extended feedback from students)

\section{Professor}

Phillips

Snyder (Dean)

Shelnutt

Allen

Graham

Graham/Middleton

Dew

Graham

Patterson

Middleton

Graham

Phillips/Leamy

Snyder

Shelnutt

Snyder

Graham

Graham

Snyder

Patterson

Graham

Phillips

Tolley/students

Allen

Graham

TBA

All faculty

All faculty

Graham/Phillips

Graham/Middleton

had the students prepare presentations for faculty masquerading as investment bankers. In a subsequent semester we experimented with a choice from several projects, from modular backyard storage buildings to toothpaste-dispensing toothbrushes, and the students' customers were faculty as engineering managers of manufacturing firms. Again, the results were very positive, both in the surprising depth and quality of the presentations and reports and in the students' (for 
the most part) enthusiastic participation. In the spring semester of 1997 student teams are designing a "people-mover" system for downtown Charlotte, North Carolina.

The "conceptual design" integral to these courses differs from the full-fledged engineering design and analysis (which one might expect to see in a capstone course) by (a) relatively more emphasis on determining the needs of the user of a product, service, or process, and (b) by emphasis on the selection of combinations of features of a design which would satisfy those needs, rather than detailed analysis and implementation of such features. We find that this approach opens the door to developing creative alternatives and avoids being stymied by the beginners' lack of adequate knowledge of the more analytic engineering principles. It is also an excellent opportunity to have students take advantage of the greater creative potential of a team in creating "out-of-the-box" alternatives using the Pugh Method of comparison and successive improvement of design alternatives ${ }^{\text {iii }}$. Perhaps too often these powerful techniques are lost in the conventional engineering college emphasis on detailed engineering analysis rather than the synthesis of open-ended problems.

\section{Active Learning}

Although the teaching methods employed vary considerably with the large number of faculty participating, we have emphasized active learning techniques. These vary from "thinkpair-share" to formal arrangements in which students divide into "expert" discussion groups focused on key topics and then report back to their project teams. Occasionally the teams do oneminute presentations on assigned topics, and sometimes the entire class ranks each team's presentation effectiveness by a multi-voting process. Calling randomly on individuals and teams to report on any assignment helps to facilitate active learning exercises in the large classes.

\section{Using the HBDI}

The first and last objectives listed above for ENGR 1201 are facilitated by having each student take the Herrmann Brain Dominance Instrument (HBDI) early in the course. The HBDI, developed by Ned Herrmann in the 1970's ${ }^{\mathrm{v}}$, and validated by fifteen years of research with tens of thousands of subjects, has become a recognized tool for many businesses in this country and abroad (Figure 2). This instrument has been used successfully to assign engineering students to teams ${ }^{\mathrm{vi}}$ and for enhancing their productivity in teamwork ${ }^{\text {vii }}$.

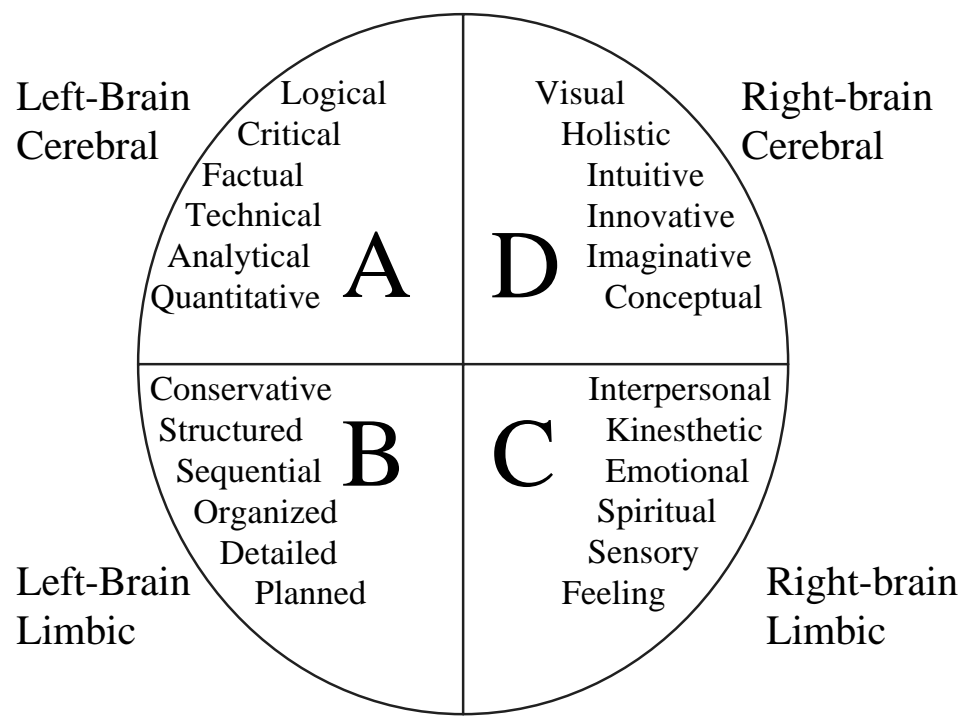

Figure 2. Illustration of The Four Quadrant Brain Model of Thinking Preferences ${ }^{\mathrm{V}}$ 
Essentially, the HBDI resolves thinking patterns into four quadrants, based on the dichotomies of right-left and cerebral-limbic, as shown in Figure 2. The upper left quadrant A represents left-brain cerebral preferences for thinking, the lower left quadrant B represents leftbrain limbic preferences, the lower right quadrant $\mathrm{C}$ represents right-brain limbic preferences, and the upper right quadrant $\mathrm{D}$ represents right-brain cerebral preferences.

As reported elsewhere in detail ${ }^{\text {viii }}$, each student is given his or her own HBDI profile and encouraged to share the results with team members. It quickly becomes obvious to all that even though the various individuals likely do not have preferences for thinking in all quadrants, the team as a whole is much better equipped. The task then becomes how to tap into the team's multifaceted thinking abilities, to create genuine mutual interdependence. This sets the stage for learning and applying creative thinking skills, becoming aware of impediments to creativity and countering them, and using the team's diversity as a strength. Classroom discussion also focuses on the challenge presented to each individual, how to serve the team with his or her unique thinking preferences and skills, and how to be open to the contributions of others with thinking styles not preferred, or perhaps even avoided, by oneself.

In the first offering of ENGR 1201, we experimented with both the HBDI and the Meyers Briggs Type Indicator (MBTI), but we came to the conclusion that the students were able to relate the structure of the HBDI to their challenges of teamwork and communication more effectively than with the MBTI. They sometimes had difficulty remembering the dimensions and implications of various profiles of the MBTI (even though we had excellent, trained facilitators to assist us in presenting the results), whereas they seemed to quickly grasp and use the quasiphysical structure of the HBDI.

\section{ENGR 1202 Learning Objectives}

The structure of ENGR 1202 allows us to consolidate and build student confidence, and to take the first step toward "institutionalizing" the team skills and creative problem solving thrusts begun in ENGR 1201. Each student is now expected to choose a major discipline, if not already chosen. The course is organized around a joint class meeting and separate lab sessions for each engineering discipline. (At this point the Computer Science students are not involved in ENGR 1202, since that department already offers a course with a similar lab component.) Desired student learning outcomes for ENGR1202 include:

- Increased personal effectiveness in critical thinking and creative problem solving;

- Enhanced abilities to work productively in teams;

- Proficiency in ability to use team tools such as brainstorming, consensus building, individual talent brokering, and project planning/organization to improve team performance;

- Enhanced confidence in applying generic computer tools such as spreadsheets, presentation packages, word processors, e-mail, and use of the Internet in practical problem solving; 
- Increased awareness of personal habits and thinking styles on other team members, and the ability to adapt these preferences to enhance team effectiveness;

- Creation and acceptance in practice of a personal professional code of conduct which includes responsibilities to oneself, to the team, to the sponsor of the work, and to society;

- Extended ability and experience in making very short but quite effective technical presentations;

- Ability to use specialized computer programs or programming languages to solve problems and to make design decisions in the respective chosen fields of engineering or computer science.

Table 2 presents the spring '97 semester topical outline for ENGR 1202. The classroom sessions cover topics on creative problem solving using a text of that title ${ }^{\text {ix }}$, and provide for coaching the teams on their semester projects. These classroom sessions also stress refinement of technical communications skills, especially short technical presentations. The laboratory sessions afford each engineering department the opportunity to present topics on introductory material of interest to each and to select a semester project which will give students an experience of applying that material in the context of creative problem solving in teams. In previous semesters the civil engineering teams learned FORTRAN programming and worked on a design project concerning allocation of water resources to cities along a river. The electrical engineering teams learned $\mathrm{C}$ programming and worked on projects involving designing a fabrication process for a semiconductor device in our clean-room facility. The mechanical engineering teams worked on engineering graphics (sketching and AUTOCAD), and worked on projects involving conceptual design of products such as a bug sprayer or a can crusher. As in ENGR 1201, the final semester presentations were conducted in an atmosphere of realism, in that students were told that they would be speaking to engineering managers (faculty) to whom they would "sell" their design or problem solution.

\section{Peer Evaluation System}

Early on we recognized the need for an efficient system of feedback among team members if they were to grasp the fundamentals of mutually supportive teamwork, individual and team responsibilities, and effective communication, all essential to effective teams. Students were given tools for these processes, including Steven Covey's 7 Habits (Covey, 1990) and the HBDI, but we felt that a workable, anonymous feedback system would be invaluable. During the first offering in 1995, we developed a computer program for our networked computer system which allowed each student to rate anonymously each of his or her team members by apportioning 100 points among them to reflect each member's contribution to the team project. The system also allowed each student to give anonymous written feedback on any aspect of team members' performance. To encourage only constructive feedback, negative or positive, and to disallow "flaming" of team members, the feedback inputs are monitored by a faculty member before being consolidated and e-mailed back to each team member. The final total of points assigned to each team member by his or her teammates make up a portion of the final individual grades. However, interpretation of the points totals is not straightforward, since a highperformance team may have team members with virtually identical (modest) point totals, while a mediocre team member in a poor or dysfunctional team may have a very high point total. We 
have experimented with normalizing the point totals in various ways, but have not yet found a solution which obviates the

Table 2 - Topical Outline for ENGR 1202 Engineering Practice and Principles II as of Spring Semester, 1997. (2 sessions per week in a 15 Week semester)

$\underline{\text { Session }}$ Topic

Professor

1 Introduction; goals and format; grading criteria; expectations for written communications; 1201 refresher and lessons learned. Tolley

2 Review of HBDI; The (Lumsdaine) 5-Step Problem Solving Process Tolley

3-5 Separate Disciplinary Lab Sessions (Civil, Electrical, Mechanical) Lab Instructors*

6 Team Assignments; project descriptions; format for final presentations and reports; project planning; effective team meetings; group dynamics. Tolley

7-9 Separate Disciplinary Lab Sessions (Civil, Electrical, Mechanical) Lab Instructors*

10 Peer evaluation \#1; giving and receiving feedback; HBDI interpretation; design objectives and constraints; Pugh Method revisited; weighted design criteria.

Tolley

11-13 Separate Disciplinary Lab Sessions (Civil, Electrical, Mechanical)

14 Team HBDI profiles; critical thinking; decision making techniques.

15-17 Separate Disciplinary Lab Sessions (Civil, Electrical, Mechanical)

18 Peer Evaluation \#2; 2-minute oral presentations on project progress; written draft of progress, report \#1; mid-term course evaluation.

19-21 Separate Disciplinary Lab Sessions (Civil, Electrical, Mechanical)

22 Solution implementation and follow-up; selling your ideas.

Lab Instructors*

Tolley

Lab Instructors*

23-25 Separate Disciplinary Lab Sessions (Civil, Electrical, Mechanical)

26 Peer evaluation \#3; preparation for final report and presentations

27-28 Team presentations to faculty panels.

29 Feedback on project presentations

Tolley

Lab Instructors*

Tolley

Lab Instructors*

Tolley

All faculty

Tolley

30 Final comprehensive examination on both class and lab materials Tolley

* for civil, electrical, and mechanical engineering breakout sessions.

need for faculty examination of the totals in context of each team's size and performance level. Nonetheless, the peer evaluation system is clearly serving a need by providing feedback to the students at two or three points during the semester, and, although we do not yet have statistical evidence to support the contention, it seems to foster radical improvements in individual performance commencing after evaluations are returned, especially the first of the series.

\section{Faculty Team Operation}

The lead instructor positions for both 1201 and 1202 have rotated among the faculty. After the lead instructor for either course is identified, he or she spends the first semester observing how the course is taught with no other real commitment required. The subsequent semester is spent teaching only the teamwork module (under the auspices of the current lead 
instructor), and it is only in the final semester of commitment that the lead instructor assumes total responsibility for the course. This process of observing, teaching the teamwork module, and then assuming lead responsibility requires less commitment from the faculty member, and it also perpetuates a more thorough understanding of the course material, particularly the team modules, among the participating faculty.

Although this system seems to work quite well, we know that we face the familiar problem of finding ways for faculty to receive recognition through the faculty reward system for work of this nature, which is quite demanding of faculty time. In addition to asking Promotion and Tenure committees to assess the value of the new curriculum dimensions in teamwork and creative problem solving, we now must ask that they resolve individual contributions to a team venture, a process that is far from settled on most campuses. Fortunately, we have the strong support of our Dean, who has backed the 1201/1202 initiative from its inception. Even more fortunately, it has turned out to be satisfying and fun to work with the team.

\section{Team Assignments}

We have experimented with various methods of assigning students to project teams. We have used the HBDI in an earlier semester ${ }^{\text {vi }}$ to balance the teams with respect to thinking preferences, and we would likely continue to use this method except that we wanted to assign team members very early in the semester, before HBDI results were available. Team sizes have ranged from four to eight members, again keeping each team's makeup as interdisciplinary as possible. Recently in ENGR 1201 we have randomly assigned (with disciplinary balance) members to teams of size seven or eight, although with early assignments there are inevitably changes in size due to students dropping and adding the class after its start. A major constraint against smaller team size is the number of presentation time-slots available at the end of the semester for final project presentations. Although faculty may differ on the question of optimum team size, there seems to be uniform agreement, based on experience, that allowing students to choose their own team members is the least preferable assignment method. Reasons cited include judgments based on friendships rather than team needs, lack of diversity in teams, and leaving out people who would be good team members but may not be assertive in the first few class sessions.

\section{Continuous Improvement}

Many of the features of this course sequence are built around the tenets of Continuous Quality Improvement (or TQM, Total Quality Management). We have incorporated feedback mechanisms at various stages within the courses, and we conduct an extensive required student evaluation of ENGR 1201 as the final examination. This evaluation includes questions on the instructors, the format, the team experience, the project, and many open-ended questions for suggested improvements. The outlines of topics have undergone continuous, if not extensive, revision each time the courses are offered. All changes, however, are made by consensus of the $1201 / 1202$ team. Typically the lead instructor for one of the courses proposes changes for the next semester based on feedback from the students or from the faculty participating in the project

presentation evaluations. Since there are always many suggestions for material to be added to the syllabus, and there are no open sessions, hard decisions must be made as to what will be eliminated when something is added. Open and candid discussions about what is working, what 
is not, and a sober appraisal of opportunities for improvement typically lead to a consensus for syllabus changes among team members. The ENGR 1201 syllabus (Table 1) has reached a level of maturity in which the changes each semester are less extensive than in the first two semesters. Early evaluation of the course by students and faculty led to improvements such as decreasing the number of assignments, coordinating assignments among participating faculty, and linking the assignments more closely to the semester project. Recent improvements include recruiting class monitors to assist in the management of attendance records, distributing handouts, time-keeping for student presentations including 5-minute reviews and other class management functions. Topical elements added include patents and invention disclosures, a lecture on project planning, a session on resume writing/updating and job searching, and one on library research for engineers. These additions were accommodated primarily by a reduction in the number of sessions allocated to professional development perspectives on the field of engineering.

Lectures of ENGR 1201 are now being videotaped for use in distance learning via cable TV to local and regional prospective students within the UNC Charlotte area in the fall of 1997. Perhaps one of the most interesting changes is that we have opened ENGR1201 to high school seniors (potential future freshmen). In the spring of 1997, we enrolled seven high school seniors in ENGR 1201. All of these students have GPA's greater than 3.1/4.0. One of them is the valedictorian designate for her class. All seven students plan to continue as freshmen engineering students at UNC Charlotte following graduation from high school.

ENGR 1202 lags a couple of semesters, and is experiencing more significant changes. In the spring of 1997, the ENGR 1202 topical outline was modified to move from a ratio of one class session to one lab session to a ratio of 9 class sessions to 18 lab sessions. The disciplinary lab instructors felt that they needed more time to cover their respective topics adequately, and the class instructors felt that they could do the job of coaching the teams on the semester projects (and introducing some new material on creative problem solving) with fewer, well-timed, and focused class sessions. The result was the topical outline shown in Table 2.

\section{Lessons Learned}

We have learned some important lessons in our first two years of these initiatives, based on our observations and on the extensive feedback collected from students. These include:

- Students are excited about the fun of engineering design and creative problem solving, but they can quickly abandon team and creativity skills if not reinforced by faculty in their disciplines.

- In ENGR 1201, because students are exposed to so many faculty, definite in-charge person(s) must be in the classroom every day to provide continuity.

- There is a natural tendency to want to put too much in the courses, at the possible detriment of the fundamental course purposes - we have learned to consider carefully what we take out when we put in something new, and to make the net exchange superior.

- The semester project in both courses is the cohesive factor providing the rationale and motivation for applying the other material. These projects should be clearly-defined, 
open-ended design projects allowing students to experience the satisfaction of creating and synthesizing design solutions.

- The most elusive and demanding faculty job is to keep track of the progress of the teams on their projects, to coach them in just the right way, at just the right time, in order to maximize their chances at a productive team project experience.

- Students have a real need to understand the importance and power of diversity, both in their personal preferences for thinking styles and among the team members for their unique potentials to contribute, and a device such as the HBDI is a valuable tool in addressing this need.

\section{References}

${ }^{\mathrm{i}}$ ABET, Criteria 2000; 1996; Accreditation Board for Engineering and Technology, Inc.; 111 Market Place, Suite 1050, Baltimore MD, 21202.

${ }^{i i}$ Shelnutt, J. William, and Kim Buch; Using Total Quality Principles for Strategic Planning and Curriculum Revision; Journal of Engineering Education, July 1996; American Society for Engineering Education; Washington, DC.

iii Herrmann, Ned; The Whole Brain Business Book; McGraw Hill, New York, NY; 1996.

${ }^{\text {iv }}$ Covey, Stephen R., The 7 Habits of Highly Effective People; Simon and Schuster, 1990.

${ }^{v}$ Herrmann, Ned; The Creative Brain, The Ned Herrmann Group, Lake Lure, NC, 28746; 1988.

${ }^{\mathrm{vi}}$ Shelnutt, J. William, and Kimberly Buch, Monika Lumsdaine, Silvia Middleton, and Patricia Tolley; Using the HBDI to Form Student Teams; Proceedings, 1996 Annual Conference, American Society for Engineering Education; June 1996, Washington, DC.

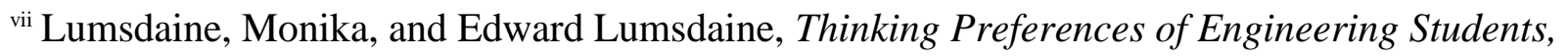
Implications for Curriculum Restructuring; J. Engineering Education, April 1995

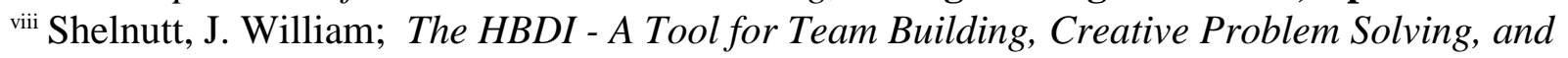
Valuing Diversity; The Innovator, Southeastern University and College Coalition for Engineering Education; NC State University, Raleigh, NC; December 1996.

${ }^{\text {ix }}$ Lumsdaine, Monika, and Edward Lumsdaine Creative Problem Solving; McGraw Hill, New York, NY; 1995 (A).

\section{Biographical Information}

William Shelnutt is an Associate Professor of Engineering Technology at UNC Charlotte. Mike Allen is a Professor of Computer Science at UNC Charlotte.

Vivek Badami is a doctoral student in Mechanical Engineering at UNC Charlotte.

Kim Buch is an Associate Professor of Industrial/Organizational Psychology at UNC Charlotte. Art Edwards is an Associate Professor of Electrical Engineering at UNC Charlotte. Curtis Ensley is a graduate student in Civil Engineering at UNC Charlotte. Johnny Graham is an Assistant Professor of Civil Engineering at UNC Charlotte. 
David Schmidt is a doctoral student in Mechanical Engineering at UNC Charlotte.

Silvia Middleton is Assistant Dean of The William States Lee College of Engineering.

Howard Phillips is an Associate Professor of Electrical Engineering at UNC Charlotte.

Patricia Tolley is a Faculty Associate and Director of Mentoring Programs at UNC Charlotte.

Monika Lumsdaine is a Faculty Associate at Michigan Technological University. 